\title{
Skin Manifestations of HIV Infection in Children in Pediatric Services of Conakry University Hospital (Guinea)
}

\author{
M. M. Soumah ${ }^{1 *}$, M. A. Bangoura ${ }^{2}$, M. Keïta ${ }^{1}$, T. M. Tounkara1 ${ }^{1}$, B. F. Diané ${ }^{1}$, D. Sylla ${ }^{3}$, H. Baldé1, \\ F. B. Sako ${ }^{4}$, F. Keïta ${ }^{1}$, M. Cissé ${ }^{1}$ \\ ${ }^{1}$ Department of Dermatology-STD in the University Hospital of Donka, Conakry, Guinea \\ ${ }^{2}$ Derpartment of Paediatry in the University Hospital of Donka, Conakry, Guinea \\ ${ }^{3}$ Department of Intensives Cares, Medico-Surgeon Urgences in the University Hospital of Donka, Conakry, Guinea \\ ${ }^{4}$ Department of Tropical Infection Diseases in the University Hospital of Donka, Conakry, Guinea \\ Email: *medsoum7@yahoo.fr
}

How to cite this paper: Soumah, M.M., Bangoura, M.A., Keïta, M., Tounkara, T.M., Diané, B.F., Sylla, D., Baldé, H., Sako, F.B., Keïta, F. and Cissé, M. (2018) Skin Manifestations of HIV Infection in Children in Pediatric Services of Conakry University Hospital (Guinea). Journal of Cosmetics, Dermatological Sciences and Applications, 8, 39-46.

https://doi.org/10.4236/jcdsa.2018.82007

Received: January 29, 2018

Accepted: April 23, 2018

Published: April 26, 2018

Copyright $\odot 2018$ by authors and Scientific Research Publishing Inc. This work is licensed under the Creative Commons Attribution International License (CC BY 4.0).

http://creativecommons.org/licenses/by/4.0/ (c) (i) Open Access

\begin{abstract}
Introduction: Dermatological manifestations during HIV infection play a diagnostic and prognostic role. They are observed in $83 \%-98 \%$ of patients at the late stage of AIDS and $58 \%-75 \%$ at an early stage of AIDS. The objective of this study was to determine the prevalence of skin diseases in HIV in children, describes the demographic profile and identify key dermatoses. Material and methods: This was a prospective study of descriptive kind conducted from August 25, 2009 to February 25, 2010. It involved children infected with HIV followed in pediatric services at the University Hospital of Conakry. All children were examined by an experienced dermatologist. The diagnosis of dermatosis was made according to the clinical signs. The stages of HIV infection were determined according to the WHO classification. Each child received retroviral serology rapid tests according to national algorithm. Results: Among 119 HIV-positive children 65 showed mucocutaneous manifestations, there are 34 girls and 31 boys, all HIV-1 infected with $66.16 \%$ in stage III disease. The average age was 7 years, ranging from 11 months to 15 years. $66.15 \%$ of the children were from married mothers and more than half of the mothers were illiterate. They were all positive for HIV1. Oral candidiasis (38.46\%), prurigo (29.23\%) and molluscum contagiosum (7.69\%) were the most common skin diseases; $52.31 \%$ had at least two associated dermatoses. The candidiasis-prurigo combination (26.47\%) was the most common. Dermatosis was often associated with other conditions: malaria (30.76\%), pulmonary tuberculosis (25.61\%) and malnutrition (12.30\%). Discussion: With 65 cases diagnosed in six months our study shows that skin diseases are common in HIV among children in Guinea. The prevalence and socio-demographic
\end{abstract}


characteristics are close to those reported by sub saharian and North African authors. A special feature of the study is that most mothers are illiterate and are infected with HIV, which would have favored the contamination of these children. Conclusion: In Sub-Saharan Africa where the rate of pediatric HIV infection is increasing, it is important to identify the mucocutaneous manifestations for optimal care.

\section{Keywords}

Skin Manifestations, HIV Infection, Children, Epidemiology, Paediatry

\section{Introduction}

The dermatological manifestations associated with HIV infection and AIDS are very frequent, sometimes even present in $100 \%$ of cases [1] [2]. They play a diagnostic and prognostic role. They are among the most visible clinical manifestations of HIV infection. In early HIV infection, most of the mucocutaneous dermatoses are similar to those observed in the non infected children. With progressive immunosuppression, mucocutaneous eruptions, become more common and include patterns which are atypical, difficult to diagnose and resistant to treatment. Candida albicans infection presenting as extensive oral thrush or recalcitrant monilial diaper dermatitis is the most common and often the first manifestation of paediatric HIV infection. Bacterial infections including severe forms of staphylococcal impetigo, ecthyma and furuncles are also common. Extensive molluscum contagiosum, Herpes simplex infection and plane warts are also common with lesions which are more widely distributed and very difficult to treat [3].

In tropical areas, some dermatoses are often indicative of HIV infection [4] [5]. In Sub-Saharan Africa, the prevalence of mucocutaneous disorders in paediatric HIV ranges from $72.6 \%$ to $96.5 \%$ [4] [6].

The data currently with regard to the mucocutaneous manifestations of HIV infection in pediatric population come mainly from the western literature. The prevalence of mucocutaneous manifestations in children with HIV infection, from various parts of the world, is highly variable, ranging from as low as $42 \%$ to almost 93\% [3] [7].

There are no data regarding prevalence and patterns of mucocutaneous disorders among HIV infected children in Guinea. The objective of this study was to determine the frequency of skin manifestations in pediatric HIV, to describe the demographic profile of affected children and identify key dermatoses encountered.

\section{Material and Methods}

This was a descriptive prospective study conducted from August 25, 2009 to 
February 25, 2010. It concerned children infected with HIV followed in the pediatric department of Conakry University Hospital.

All participants were interviewed to obtain demographic and clinical information. Dermatological examination was done in daylight. Diagnoses of most dermatoses were done clinically. Where necessary, appropriate laboratory tests like skin scrapings, pus swabs and skin biopsies were performed to confirm the diagnoses. Each child has been tested and confirmed using triple enzyme-linked immunosorbent assay according to the national algorithm. Clinical staging was done according to the WHO paediatric staging of HIV/AIDS [8]. We included all HIV positive children with skin manifestations. Data collection was done from a previously established survey sheet. We studied the frequency of dermatoses, the demographic profile (age, sex, origin, educational level and marital status of mothers) of children, the serological status of mothers, the stage of HIV infection, the type of dermatosis and associated diseases. The data analysis was done using Epi info 7.1.5.0.

\section{Results}

Among 119 HIV-positive children identified, 65 (54.62\%) had cutaneous and mucosal manifestations, 34 girls and 31 boys, all of whom had HIV-1. The average age was 7 years, ranging from 11 months to 15 years. The age groups 1 - 5 years (40\%) and 10 - 15 years (22\%) were the most affected. Their sociodemographic profile is shown in (Table 1). 66.15\% of the children were in clinical stage III according to the WHO classification. $66.15 \%$ of the children were from married mothers and more than half of the mothers were illiterate. They were all HIV-1 positive. $38.46 \%$ of the children were inhabitants of the municipality of Matoto (the most populated of the capital). The most common dermatoses were oral candidiasis (38.46\%), prurigo (29.23\%), molluscum contagiosum and herpes zoster (7.69\% each) (Table 2). $52.31 \%$ of the children had at least two associated dermatoses. The candidiasis-prurigo combination (26.47\%) was the most common. Dermatosis was often associated with other conditions: malaria in 20 (30.76\%) cases, pulmonary tuberculosis in 16 (25.61\%) and protein-energy malnutrition 8 (12.30\%) (Table 3). All the HIV-positive children received antiretroviral treatment for the treatment of HIV but also a specific treatment for each opportunistic infection. We recorded 11 (16.92\%) deaths, 5 (7.69\%) was lost of follow-up and 49 (75.38\%) cases of favorable evolution.

\section{Discussion}

Our study, although conducted in a small series over a short period (6 months), gives the demographic and clinical characteristics of children infected with HIV and presenting mucocutaneous manifestations in the pediatric departments of the Conakry University Hospital. Our results certainly can not represent all children infected with HIV in Guinea, but they give an idea of the importance of skin manifestations during pediatric HIV in Conakry. With a frequency of 
Table 1. Sociodemographic characteristics of $65 \mathrm{HIV}$ positive children.

\begin{tabular}{|c|c|c|}
\hline & $\mathrm{N}$ & $\%$ \\
\hline \multicolumn{3}{|l|}{ Age (years) } \\
\hline $0-5$ & 38 & 58.46 \\
\hline $6-10$ & 13 & 20.00 \\
\hline $11-15$ & 14 & 21.54 \\
\hline \multicolumn{3}{|l|}{ Sex } \\
\hline Males & 31 & 47.7 \\
\hline Females & 34 & 52.30 \\
\hline Sex-ratio & 0.91 & \\
\hline \multicolumn{3}{|c|}{ Geographical distribution } \\
\hline Urban & 58 & 89.23 \\
\hline Rural & 7 & 10.77 \\
\hline \multicolumn{3}{|c|}{ Marital status of monther } \\
\hline Married & 43 & 66.15 \\
\hline Unmarried & 9 & 13.85 \\
\hline Widow/Separeted & 13 & 20.00 \\
\hline \multicolumn{3}{|l|}{ HIV status of mother } \\
\hline HIV positive & 65 & 100 \\
\hline HIV negative & 0 & \\
\hline
\end{tabular}

Table 2. Skin and mucocutaneous disorders in 65 HIV-seropositive children.

\begin{tabular}{ccc}
\hline Skin and mucocutaneous disorders & $\mathrm{N}$ & $\%$ \\
\hline Infectious dermatosis & 47 & 72.30 \\
Candidiasis & 25 & 38.46 \\
Dermatophytosis & 2 & 3.07 \\
Warts & 3 & 4.61 \\
Molluscun contagiosum & 5 & 7.69 \\
Herpes zoster & 5 & 7.69 \\
Herpes labialis & 1 & 1.53 \\
Folliculitis & 4 & 6.15 \\
Scabies & 2 & 3.07 \\
Non infectious dermatosis & 23 & 35.38 \\
Prurigo & 19 & 29.23 \\
Kaposi sarcoma & 2 & 3.07 \\
Seborrhoeic dermatitis & 2 & 3.07 \\
\hline
\end{tabular}

Table 3. Other conditions associated with skin manifestations in 65 HIV positive children.

\begin{tabular}{ccc}
\hline Other conditions & $\mathrm{N}$ & $\%$ \\
\hline Malaria & 20 & 30.76 \\
Tuberculosis & 16 & 25.61 \\
Protein-energy malnutrition & 8 & 12.30 \\
\hline
\end{tabular}


$54.62 \%$ our study shows that skin manifestations are common in pediatric HIV. However this result is not exhaustive because the study took into account only the cases of dermatoses observed in the children followed in the Conakry university hospital. Authors from the West African sub-region [4] report much higher frequencies of $96.5 \%$ in Ouagadougou (Burkina Faso). While Lim W et al. [7] reported a frequency of $100 \%$. The socio-demographic characteristics of our series were comparable to those of other African authors, notably that of Traore A et al. [4] who report that cutaneo-mucosal manifestations of pediatric HIV were more common in children aged 18 - 35 months and 3 - 15 years; as well as that of Panya MF et al. [9] in Tanzania also report the same age groups. The predominance of girls may be due to the fact that they were the most numerous at the consultation during the study period. Moreover, the same observation is made in the series of Traore A et al. [4] in Burkina Faso and Endayehu Y et al. [6] in Ethiopia. WHO clinical stage III indicates the late detection of HIV infection in these children. This is linked to the inadequacy of the prevention of mother-to-child transmission (PMTCT) program and the low intellectual level of mothers. Which would probably have promoted the transmission of HIV to these children.

In this study infectious dermatosis are the most frequent cause of mucocutaneous disorders among HIV infected children like other studies [6] [9]. The increased incidence of skin infections is attributed to the depletion of the Langerhan's cells responsible for the mucocutaneous immunological system [10].

Fungal infections are the most common cutaneous presentation, with a reported prevalence of $44 \%$ to $69 \%$ [7] [10]. They are at the forefront of cutaneo-mucosal manifestations in HIV-infected children [2] [5] [6] [11] [12]. However in the study of Mittal S et al. [5], fungal infections were the second most common infection, with a prevalence of $11.4 \%$.

In our study the most frequently encountered dermatoses were oral candidiasis (38.46\%), prurigo (29.23\%) and molluscum contagiosum (7.69\%). Lim W et al. [7] and Stracka BF et al. [13] in the USA observed similar results. The involvement of the oropharyngeal mucosa is the most frequent candidiasis site. It is seen all the more as the immunodeficiency is severe. It is the most frequently mucosal manifestation observed during AIDS in children. Isolated oral disease is a marker of minor immunodeficiency but associated with oesophageal involvement and is a classification criterion for AIDS [14]. It is almost always due to Candida albicans. Two clinical forms of oral candidiasis are observed: pseudomembranous type, and atrophic erythematous type. The pearlescent and the cheilite are compared. Thrush is most commonly seen with confluent, whitish "curdled" patches covering the tongue, palate, juxalian mucosa, and tonsils [12] [14] [15]. As for prurigo, in addition to immunosuppression, particular environmental factors may explain its high frequency in Africa. The possible role of insect bites, not directly but by an immunoallergic mechanism is evoked in children, it is necessary to eliminate a prurigo strophulus reaching the young 
Table 4. The different epidemiological and clinical data based on locations/studies.

\begin{tabular}{|c|c|c|c|}
\hline \multirow{3}{*}{ Values } & \multicolumn{3}{|c|}{ Studies } \\
\hline & Our study & Panya MF et al [9] & Endayehu et al [6] \\
\hline & $\mathrm{N}=65$ & $\mathrm{~N}=347$ & $\mathrm{~N}=270$ \\
\hline Age groupes & $\mathrm{n}(\%)$ & $\mathrm{n}(\%)$ & $\mathrm{n}(\%)$ \\
\hline $0-5$ & $38(58.46)$ & $105(30)$ & $36(13.3)$ \\
\hline 6- 10 & $13(20.00)$ & $155(45)$ & $101(37.4)$ \\
\hline $11-15$ & $14(21.54)$ & $75(22)$ & $133(49.2)$ \\
\hline$>15$ & & $12(3)$ & \\
\hline Sex & $\mathrm{n}(\%)$ & $\mathrm{n}(\%)$ & $\mathrm{n}(\%)$ \\
\hline Males & $31(47.7)$ & $180(52)$ & $131(48.5)$ \\
\hline Females & $34(52.30)$ & $167(48)$ & $139(51.5)$ \\
\hline Sex-ratio & 0.91 & 1.07 & 0.94 \\
\hline WHO paediatric stage & $\mathrm{n}(\%)$ & $\mathrm{n}(\%)$ & $\mathrm{n}(\%)$ \\
\hline Stage III & $43(66.15)$ & $166 / 294(94)$ & $80 / 196(78)$ \\
\hline Skin disorder & n (\%) & $\mathrm{n}(\%)$ & n (\%) \\
\hline Infectious dermatosis & $47(72.30)$ & $256(73.77)$ & $162 / 196(82.6)$ \\
\hline Non infectious dermatosis & $23(35.38)$ & $189(54.46)$ & $88 / 196(44.8)$ \\
\hline
\end{tabular}

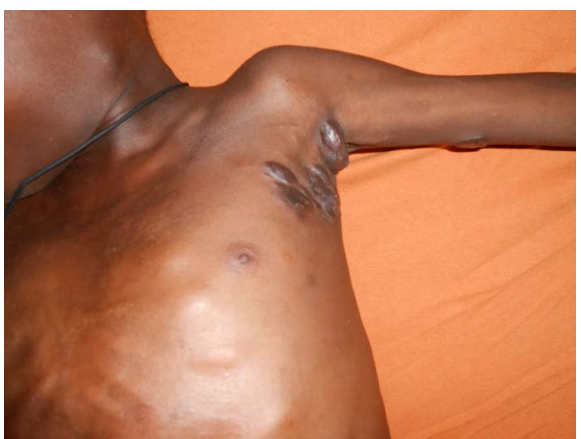

(a)

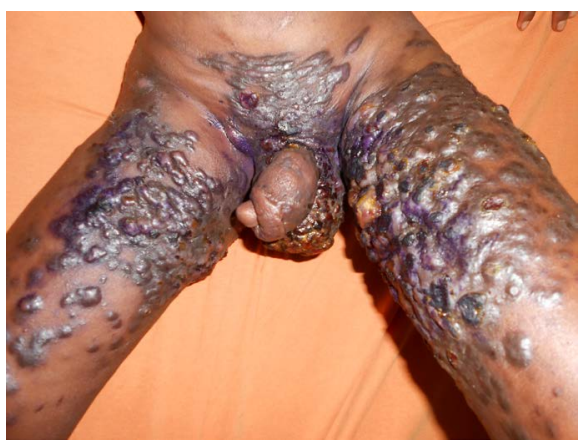

(b)

Figure 1. Kaposi sarcoma in a 10 years-old child HIV positive. (a) Nodular lesions in the axilla; (b) Infiltrated populo-nodular lesions with genital involvement.

child and sometimes the young adult [3] [16]. It should be added that the high frequency of these dermatoses may be related to the fact that their occurrence is often independent of the level of immunosuppression. The dermatoses can therefore appear at any stage of the evolution of the disease. The different epidemiological and clinical data based on locations/studies in Table 4.

In our study, Kaposi's sarcoma (KS) was seen in two children (Figure 1) indicating that this malignancy is rare among HIV infected children, which is similar to what was reported by El Hachem M et al. [3] and Panya MF et al. [9] who reported only one case. However, other studies have reported a significant rise in childhood KS among HIV infected children. Ziegler et al. reported that the incidence of KS had risen more than 40 -fold in the era of HIV [17]. Similarly Athale 
$\mathrm{OH}$ et al observed an increased incidence of KS in HIV infected Zambian children [18].

The frequent association of dermatoses with other pathologies including malaria, is the fact that our country is in a malaria endemic area and that malaria is the first reason for hospital consultation. As for tuberculosis, its association is not fortuitous because it constitutes the first opportunistic pulmonary infection observed in people infected with HIV in Africa [19] [20].

\section{Conclusion}

The frequency and richness of dermatological conditions encountered during HIV infection and AIDS show that the dermatological examination is a critical time of infection screening for HIV in Africa where the rate of pediatric infection is high. The knowledge by physicians of the major dermatological conditions evocative of AIDS in Africa will make an early diagnosis of HIV infection and provide better care.

\section{References}

[1] Dover, J.S. and Johnson, R.A. (1991) Cutaneous Manifestations of Human Immunodeficiency Virus Infection. Part I. Archives of Dermatology, 127, 1383-1391. https://doi.org/10.1001/archderm.1991.01680080119015

[2] Mendiratta, V., Mittal, S., Jain, A. and Chander, R. (2010) Mucocutaneous Manifestations in Children with Human Immunodeficiency Virus Infection. Indian Journal of Dermatology, Venereology and Leprology, 76, 458-466. https://doi.org/10.4103/0378-6323.69041

[3] El-Hachem, M., Bernadl, S., Pianosi, G., et al. (1998) Mucocutaneous manifestation in Children with HIV Infection and AIDS. Pediatric Dermatology, 15, 429-434. https://doi.org/10.1046/j.1525-1470.1998.1998015429.x

[4] Traoré, A., Niamba, P., Ouedraogo, T., Sanon, H., Sanou, I., Kam, K.L., et al. (2000) Manifestations dermatologiques au cours du SIDA pédiatrique en milieu hospitalier à Ouagadougou (Burkina Fasso). Nouvelles Dermatologiques, 19, 39-43.

[5] Mittal, S., Mendiratta, V., Kumar, P. and Chander, R. (2013) Mucocutaneous Manifestations in Indian Children with Human Immunodeficiency Virus Infection. Pediatric Dermatology, 30, e274-275. https://doi.org/10.1111/pde.12167

[6] Endayehu, Y., Mekasha, A. and Daba, F. (2013) The Pattern of Mucocutaneous Disorders in HIV Infected Children Attending Care and Treatment in Tikur Anbesa Specialized Hospital, Addis Ababa, Ethiopia. BMC Dermatology, 13, 12. https://doi.org/10.1186/1471-5945-13-12

[7] Lim, W., Sadick, N., Gupta, A., Kaplan, M. and Pahwa, A. (1990) Skin Diseases in Children with HIV Infection and Their Association with Degree of Immunosuppression. International Journal of Dermatology, 1, 24-30. https://doi.org/10.1111/j.1365-4362.1990.tb03750.x

[8] World Health Organisation (2007) WHO Case Definitions of HIV for Surveillance and Revised Clinical Staging and Immunological Classification of HIV-Related Disease in Adults and Children. WHO, Geneva, 11-17.

[9] Panya, M.F., Mgonda, Y.M. and Massawe, A.W. (2009) The Pattern of Mucocu-Taneous Disorders in HIV-Infected Children Attending Care and Treatment 
centres in Dar es Salaam, Tanzania. BMC Public Health, 9, 234.

https://doi.org/10.1186/1471-2458-9-234

[10] Oliveira de Carvalho, V., Marinoni, L.P., Martin, F., et al. (2003) Dermatological Alterations in Children with AIDS and Their Relation to Clinical-Immunological Categories and Viral Load. Anais Brasileiros de Dermatologia, 78, 679-692.

[11] Fisher, B.K. and Warner, L.C. (1987) Cutaneous Manifestations of the Acquired Immunodeficiency Syndrome. International Journal of Dermatology, 10, 615-630. https://doi.org/10.1111/j.1365-4362.1987.tb02267.x

[12] Janier, M. (1988) Manifestations cutanées de l'infection par le VIH. Récherches Dermatologiques, 1, 7-37.

[13] Straka, B.F., Whitaker, D.L., Morrison, S.H., Oleske, J.M. and Grant-Kels, J.M. (1988) Cutaneous Manifestations of the Acquired Immunodeficiency Syndrome in Children. Journal of the American Academy of Dermatology, 18, 1089-1102. https://doi.org/10.1016/S0190-9622(88)70112-7

[14] Janier, M. and Caumes, E. (2004) Signes cutanés de l'infection par le virus de l'immunodéficience humaine. Editions techniques. Encyclopedie Médico-chirurgicale Dermatologie, 12-680-A-I0, 12.

[15] Vohito, M.D., Koyada, R., Normand, P., Testa, J., Belec, L., Di Constanzo, B., et al. (1994) Les manifestations dermatologiques associées au syndrome d'immunodéficience acquise en Afrique centrale. Médecine Tropicale, 54, 438-439.

[16] Ndiaye, B., Dieng, M.T. and Develoux, M. (1997) Manifestations dermatologiques de l'infection par le VIH: Mise au point sur 5 ans (1991-1995) à Dakar. Les Nouvelles Dermatologiques, 16, 10.

[17] Ziegler, J.L. and Katongole-Mbidde, E. (1999) Kaposi's Sarcoma in Childhood: An Analysis of 100 Cases from Uganda and Relationship to HIV Infection. International Journal of Cancer, 65, 200-203.

https://doi.org/10.1002/(SICI)1097-0215(19960117)65:2<200::AID-IJC12>3.0.CO;2$\underline{\mathrm{H}}$

[18] Athale, O.H., Patil, P.S., Chintu, C. and Elem, B. (1995) Influence of HIV Epidemic on the Incidence of Kaposi's Sarcoma in Zambian Children. Journal of Acquired Immune Deficiency Syndromes and Human Retrovirology, 8, 96-100. https://doi.org/10.1097/00042560-199501000-00014

[19] Sindrup, J.H., Lisby, G., Weismann, K. and Wantzin, G.L. (1987) Skin Manifestations in AIDS, HIV Infection, and AIDS Related Complex. International Journal of Dermatology, 5, 267-272. https://doi.org/10.1111/j.1365-4362.1987.tb00186.x

[20] Rosenheim, M., M’pele, P., Itoua-Ngaporo, A., Brucker, G., Duflo, B. and Gentilini, M. (1988) Propositions Pour une stratégie diagnostique et thérapeutique de l'infection à VIH en Afrique. Medecine d Afrique Noire, 34, 1021-1030. 